\title{
Effect of Low-Velocity Non-Darcy Flow on Well Production Performance in Shale and Tight Oil
} Reservoirs

\author{
Xiukun Wang and James J. Sheng* Texas Tech University \\ *Corresponding author. Email: james.sheng@ttu.edu, Tel: 8068348477
}

\begin{abstract}
There are many core flooding studies showing that the liquid-measured permeability is lower
\end{abstract} than the Klinkenberg-corrected gas permeability. The flow velocity in a low pressure gradient regime is lower than what is estimated from Darcy's law. This phenomenon is considered as low-velocity non-Darcy flow in the literature. Besides, many researchers believe that there is a threshold pressure gradient (TPG) that needs to be overcome before the fluid flow can occur. The related results in the literature are critically reviewed in this paper. By analyzing the flow mechanism, considering boundary effect, and presenting counter examples, we conclude that the low-velocity non-Darcy flow regime consists of a nonlinear flow part and a linear flow part. The nonlinear flow part starts from the zero pressure gradient instead of TPG. Based on this observation, a non-Darcy model is introduced and the corresponding correlation parameters are derived by fitting the available experimental data. This model is used to estimate the well performance of a vertical well and a multi-fractured horizontal well. For a vertical well, the production rate of non-Darcy flow is much smaller than that of Darcy flow, and the ultimate oil recovery of non-Darcy flow is approximately $48 \%$ of the Darcy flow. The production rate of a multi-fractured horizontal well if non-Darcy flow is considered is smaller in the beginning but greater than the corresponding Darcy flow rate after about some time (in our example model, 2700 days). The ultimate recovery factor of non-Darcy flow is $80 \%$ of Darcy flow, which indicates that multi-fractured wells are less affected by the low-velocity non-Darcy phenomenon compared with the vertical wells. Multi-fractured horizontal wells exhibit a significant advantage in developing shale and tight reservoirs, and low velocity non-Darcy flow plays a significant impact on the well production performance in tight and shale reservoirs.

Keywords: Low velocity non-Darcy flow; Threshold pressure gradient; Well production performance; Shale oil; Tight oil

\section{Introduction}

With the development of tight and shale reservoirs, more and more attentions have been paid to the flow mechanisms in micro-, and even nano-pores at low fluid velocities. The interaction 
between solid molecular and the fluid molecular differentiates the flow mechanisms of the shale

2 and tight reservoirs from the conventional reservoirs. For gas flow, based on the Knudsen number and Maxwell boundary slip condition, there are several gas apparent permeability

4 models [1, 2]. Knudsen number refers to the ratio of gas molecular mean free path over pore size

5 and Maxwell boundary slip condition is the first-order approximation from kinetic theory of gases. But the Knudsen number loses its usage in liquid flow condition, so the liquid flow cannot be treated the same as gas flow in nanopores [3]. Following the studies of water flowing in

8 carbon nanotubes [4, 5], Javadpour et al. [6] measures the slip length of brine on shale slab by using AFM (Atomic Force Microscope) method. The slip length values in their experiments are in the range of several hundred nanometers with large uncertainties. Whether the concept of slip

11 length can be used to interpret practical reservoir flow is a question, as there are many core 12 flooding studies showing that the liquid measured permeability is lower than Klinkenberg corrected gas permeability [7-10]. The flow on a polished shale slab which was used in 14 Javadpour et al's study may not be representative of real shale pores. The polished shale panel had a smooth surface which would help to cause liquid slip.

On the other hand, many researchers have found that the low flow velocity in a low pressure 17 gradient regime is lower than what is estimated from Darcy's law. This low-velocity non-Darcy 18 flow phenomenon exists in low and extra low permeability reservoirs. Because the permeability of shale and tight reservoirs is so small that we practically cannot measure a very small steady state flow rate in a core-flooding experiment. What people did is to extrapolate the experimental results from higher permeability cores to shale and tight conditions. A typical schematic of lowvelocity non-Darcy flow is shown in Fig. 1. When the pressure gradient is small, there is no flow rate. As the pressure gradient becomes larger than a certain value called threshold pressure gradient (TPG), the flow occurs. As the pressure gradient is further increased, the flow rate increases and finally a linear relationship occurs as described by Darcy's law. There are three flow regimes (parts): the no flow part, the nonlinear flow part, and the linear flow part. 


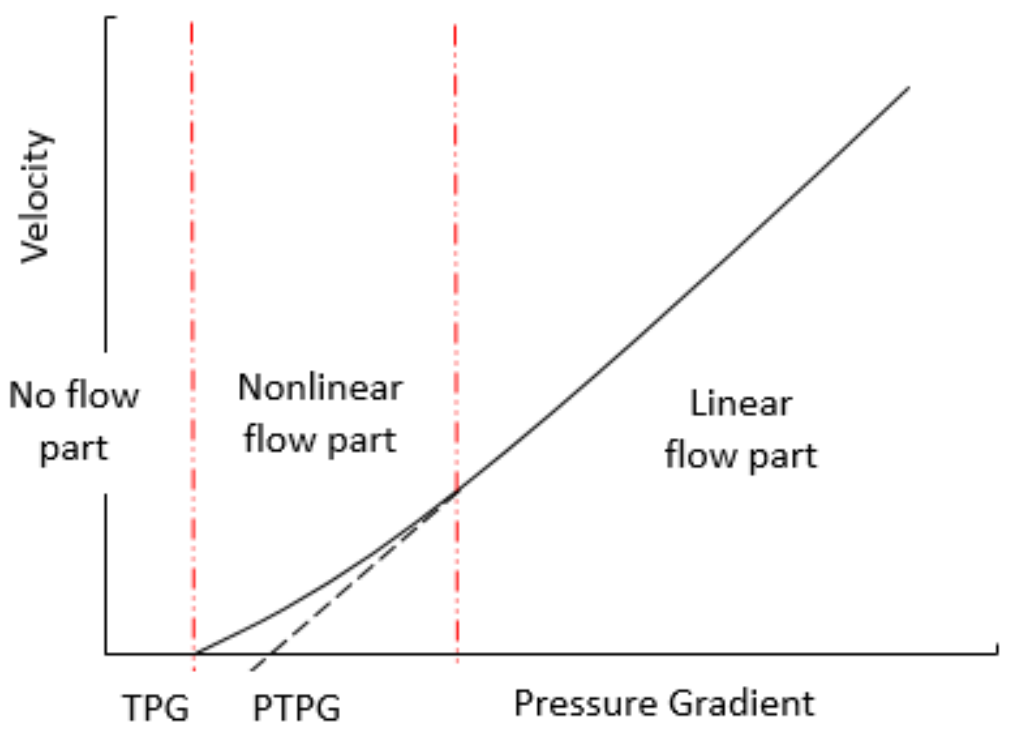

Fig. 1 A typical schematic of low-velocity Non-Darcy flow [11]

The nonlinear flow part is not measurable using a simple experimental setup. We can only measure a flow rate and a pressure gradient at reasonable high values in practice. If we extend the straight line of the linear flow part to the $\mathrm{X}$ axis (pressure gradient), it intersects with the $\mathrm{X}$ axis at a non-zero point (with a positive value). The flow phenomenon is quite similar to the Bingham fluid property. This is contradictory to Darcy's law, which states that a zero flow velocity should correspond to a zero pressure gradient. The intercepted positive value is known as the pseudo threshold pressure gradient (PTPG), as this is not the true threshold pressure gradient (TPG) owing to the existence of low-velocity non-Darcy flow part (see Fig. 1). The term PTPG is used in this paper. Miller and Low [12] are among the first researchers who studied the non-Darcy flow phenomenon in low permeability clay systems. The interacting forces between the fluid and the rock are believed to be the cause of the threshold pressure gradient. This phenomenon did not gain much attention until the late 1990s, when the development of low permeability reservoirs was started. Prada and Civan [13] studied this phenomenon using brine, and concluded that the PTPG increases with the decrease of fluid mobility. They discovered that the higher the rock permeability, the smaller the PTPG is, and the higher the fluid viscosity, the smaller the PTPG is. Based on their developed correlation, the estimated PTPG values are too large to be practically used in reservoir flow. Other PTPG correlations that were developed from similar experimental studies have the similar problem [1418]. In those studies, the PTPG values were obtained by extrapolation from a higher pressure 
gradients because of the difficulties in accurately measuring small flow rates at low pressure gradients.

With higher accurate instruments, lower pressure gradients and lower velocities can be measured. Nowadays, the nonlinear flow part is recognized and the nonlinear flow part is

5 believed to be the main flow regime in tight or shale reservoirs. This means that the nonlinear flow part needs to be carefully studied. Many studies have been done, and different experimental results and developed correlations have been reported [11, 19-22]. The non-Darcy flow behavior

8 in those studies is similar to that shown in Fig. 1. According to the studies cited above, measurable pressure gradient and velocity are becoming smaller and smaller. As a smaller pressure gradient is used, a smaller velocity is measured. But the measurable pressure gradient and velocity are ultimately limited by the accuracy of instruments. In other words, we cannot measure TPG directly; it can only be obtained by extrapolation. Then a question arise: is there a small TPG at which the velocity is zero?

In this paper, we first carefully analyze the studies related with low velocity non-Darcy flow and discuss the existence of TPG. Then a low velocity non-Darcy model is introduced and the corresponding parameter correlations are developed by fitting the experimental data. Finally, both the vertical well model and horizontal well model with multi-fractures are used to study the production performance of shale or tight reservoirs. Because the commercial simulators (ECLISPE or CMG) cannot consider this flow mechanism, we program them by using finite difference method in MATLAB environment.

\section{2. Discussion of low velocity non-Darcy flow}

The boundary effect between the rock and fluid is believed to be the main cause of low velocity non-Darcy flow. The surface force becomes an important parameter to consider for fluid flow in porous media, as the interfaces between fluids and rocks are large. The lower the permeability is, the larger the rock fluid interaction force is. Due to this force, the fluid molecules will distribute unevenly. Huang's study [14] shows that the percentage of resins and asphaltenes near the fluid-rock boundary is higher than that in the pore center, and this phenomenon is also proved by Wang et al. [23] by using molecular dynamic simulation. Also, the viscosities of the same oil in pores of different diameters are different. The smaller the pore diameter is, the higher the viscosity is. Therefore, the fluid in the pores can be divided into two 
parts, the boundary fluid and the inner free fluid (see Fig. 2). The boundary fluid will have 2 higher density and higher viscosity.

Liu et al. [24] studied the change of boundary layer thickness along with the pressure gradient by using the micro plastic particles in a centrifugal machine. He concluded that the increase in 5 the boundary thickness with the pressure gradient was the main cause of non-Darcy flow. Xu and Yue [25] studied the flow in micro tubes. The diameters of the tubes are $5 \mu \mathrm{m}$ and $2 \mu \mathrm{m}$. The experiments show that the flow mechanism in micro tubes is just like the one described in Fig. 1.

8 Although $\mathrm{Xu}$ and Yue were able to measure a flow rate as low as $3.25 \times 10^{-5} \mu \mathrm{L} / \mathrm{s}$ at a pressure gradient of $0.21 \mathrm{MPa} / \mathrm{m}$, they were not sure whether a TPG could exist.

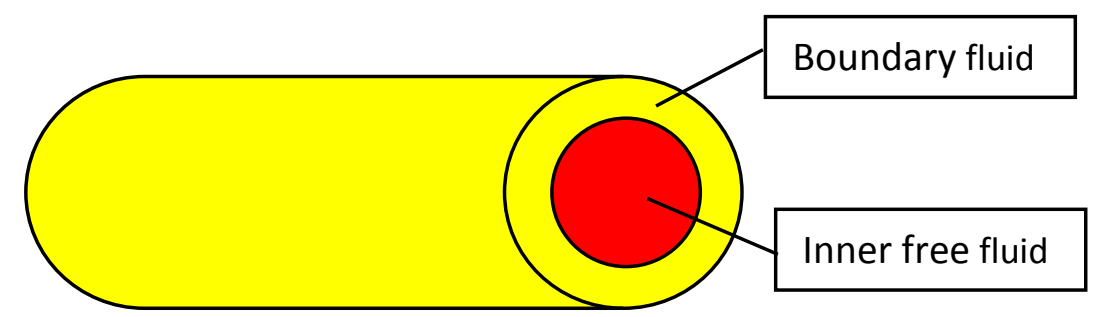

Fig. 2 Schematic of fluid in a capillary consisting of boundary fluid and inner free fluid

Suppose there is a capillary to represent the reservoir formation (c.f. Fig. 2). The boundary fluid viscosity is $\mu_{b}$, and the free fluid viscosity is $\mu$. The boundary layer thickness is $\delta$ and the pore radius is $r$. Following the derivation of the Poiseuille equation, the velocity can be derived as

$$
q=-\frac{\pi}{8} \nabla p\left(\frac{(r-\delta)^{4}}{\mu}+\frac{r^{4}-(r-\delta)^{4}}{\mu_{b}}\right)
$$

where $\nabla p$ is the pressure gradient, and $q$ is fluid rate.

If there is no boundary layer $(\delta=0)$, the equation (1) becomes the Poiseuille equation. Due to $\mu_{b}>\mu$, the velocity including the boundary layer effect is smaller than that predicted by the Poiseuille equation. When the pressure gradient increases, the boundary layer decreases, and the velocity will become closer to the Poiseuille equation velocity. This is the micro explanation of low velocity non-Darcy flow. However, there is no TPG because the boundary layer is also movable given a pressure gradient, at a velocity lower than that without the boundary layer.

Many TPG or PTPG correlations have been reported in the literature [13, 16-18, 26-30]. Some of these are summarized in Table 1. The TPG measured values are in a large range of uncertainty and most of the values are too large to be reasonable in reservoirs. For instance, in a 
radial flow to a production well, the pressure gradients far away from the well are much smaller

2 than that in the near wellbore region. If those values are valid, only in a small part of the reservoir area near the well bore can the fluid flow.

Table 1 TPG estimation formula and experimental data

\begin{tabular}{|c|c|c|}
\hline Reference & TPG formula or data, $\mathrm{MPa} / \mathrm{m}$ & Comments \\
\hline $\begin{array}{l}\text { Prada and Civan } \\
1999[13]\end{array}$ & $\mathrm{TPG}=11.03\left(\frac{k}{\mu}\right)^{-0.8}$ & Core flooding using brine \\
\hline Song et al. 2001 [26] & $\mathrm{TPG}=0.5 \sim 2.3 \mathrm{MPa} / \mathrm{m}$ & $\begin{array}{l}\text { Core flooding using oil } \\
\text { Core permeability unknown }\end{array}$ \\
\hline Liu et al. 2002 [27] & $\mathrm{TPG}=0.0168 \mathrm{MPa} / \mathrm{m}$ & Transient pressure analysis method \\
\hline Yang et al. 2004 [28] & $\mathrm{TPG}=0.001 \sim 1 \mathrm{MPa} / \mathrm{m}$ & $\begin{array}{l}\text { Core flooding using brine and oil } \\
\text { Core permeability: } \mathrm{K}=0.623 \sim 2.80 \mathrm{mD}\end{array}$ \\
\hline Yan et al. 2006 [29] & $\mathrm{TPG}=0.15 \sim 3.5 \mathrm{MPa} / \mathrm{m}$ & $\begin{array}{l}\text { Core flooding using water } \\
\text { Core permeability: } k=0.3 \sim 10 \mathrm{mD}\end{array}$ \\
\hline Hao et al. 2008 [30] & $T P G=1.46 k^{-0.5341}$ & Core flooding using oil, oil viscosity: $2.38 \mathrm{cP}$ \\
\hline Li et al. 2008 [16] & $\mathrm{TPG}=0.5\left(\frac{k}{\mu}\right)^{-0.9813}$ & Core flooding using oil, oil viscosity: $1.3 \mathrm{cP}$ \\
\hline Li et al. 2008 [17] & $\mathrm{TPG}=0.0747 k^{-1.117}$ & Core flooding using oil, oil viscosity unknown \\
\hline Zeng et al. 2011 [18] & $\mathrm{TPG}=0.4 k^{-0.9348}$ & $\begin{array}{l}\text { Core flooding using formation water } \\
\text { Water viscosity is } 0.91 \mathrm{cP}\end{array}$ \\
\hline
\end{tabular}

6 Besides, the formation and migration of the tight and shale reservoirs contradicts the existence

7 of TPG or PTPG. In a reservoir, fluid distribution follows the gravity segregation. The gravity

8 gradient is quite small compared to the TPG values, approximately less than $0.0001 \mathrm{MPa} / \mathrm{m}$. If a

9 TPG exists, hydrocarbon migration cannot happen and the reservoir cannot be formed. So, the 10 TPG cannot exist [31].

11 In conclusion, TPG doesn't exist in low velocity non-Darcy flow and there are only nonlinear

12 flow part and linear flow part in Fig. 1. The nonlinear flow starts from the origin instead of TPG.

\section{3. Modelling of low velocity non-Darcy flow}

14 Based on the previous statement, we present a low velocity non-Darcy model 


$$
v=-\frac{k}{\mu} \nabla p\left(\frac{1}{1+a \mathrm{e}^{-b|\nabla p|}}\right)
$$

2 where $k$ is permeability and $a$ and $b$ are positive coefficients which can be obtained by fitting

3 the experimental data. This model ensures that the non-Darcy flow regime starts from the origin 4 as a curve and becomes a straight line when pressure gradient is large enough. When $a=0$, 5 Equation (2) becomes Darcy's equation. When $\nabla p=0$, the term in bracket (dimensionless 6 permeability) equals to $\frac{1}{1+a}$, which is the starting permeability multiplier at zero pressure gradient. 7 Our model is applied by fitting the high accuracy experimental data [19]. In their study, they 8 used a micro-flux measuring instrument, which integrated a glass micro-tube with inner diameter 9 of $1 \mathrm{~mm}$ and an electronic digital vernier caliper. In this way, they could calculate the liquid flow velocity by measuring the moved distance of liquid level using a photoelectric sensor. The 11 pressure gradient of core was adjusted by the valve of gas tank. When the flow velocity at the 12 outlet of the rock sample reached a stable state under a specific constant displacing pressure, the moved distance of the liquid level and the time were recorded at different pressure gradient. We can get the apparent permeability values from the experimental data at any given pressure gradient by $k_{a p p}=\frac{v \mu}{\nabla p}$. In the figure, the dimensionless permeability is the ratio of the apparent permeability to the maximum apparent permeability at high pressure gradient. The markers are

17 the experimental data and corresponding solid lines are the fitting results by using the term in bracket in Eq. (2), i.e., $k^{*}=\frac{1}{1+a \mathrm{e}^{-b \nabla p}}$. The fitting results are given in Fig. 3. We can see that our model can reasonably represent the non-Darcy flow characteristics.

Also, we present the correlations of $a$ and $b$ as follows (see Fig. 4)

$$
\begin{gathered}
a=-0.6095\left(\frac{k}{\mu}\right)^{3}+2.5821\left(\frac{k}{\mu}\right)^{2}-3.4594\left(\frac{k}{\mu}\right)+1.5836 \\
b=0.3603\left(\frac{k}{\mu}\right)^{2}-0.1049\left(\frac{k}{\mu}\right)+1.0935
\end{gathered}
$$




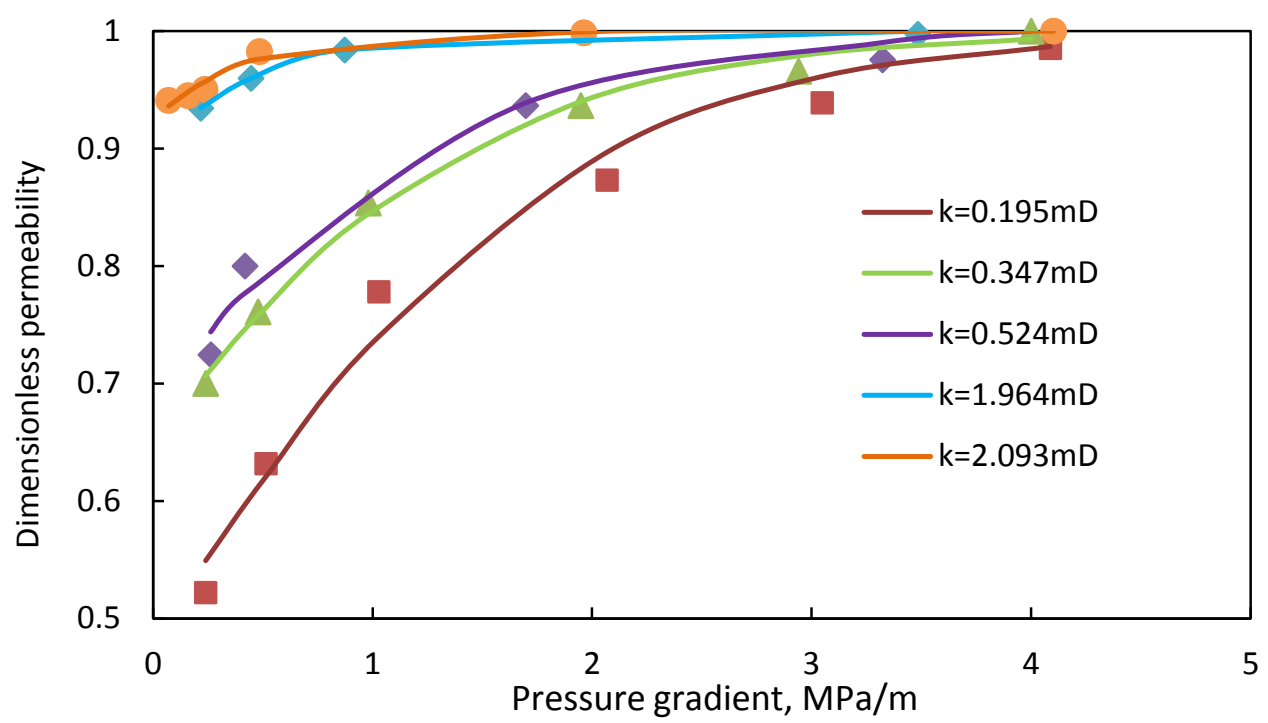

1

Fig. 3 One curve fitting result of the experimental data by using our model

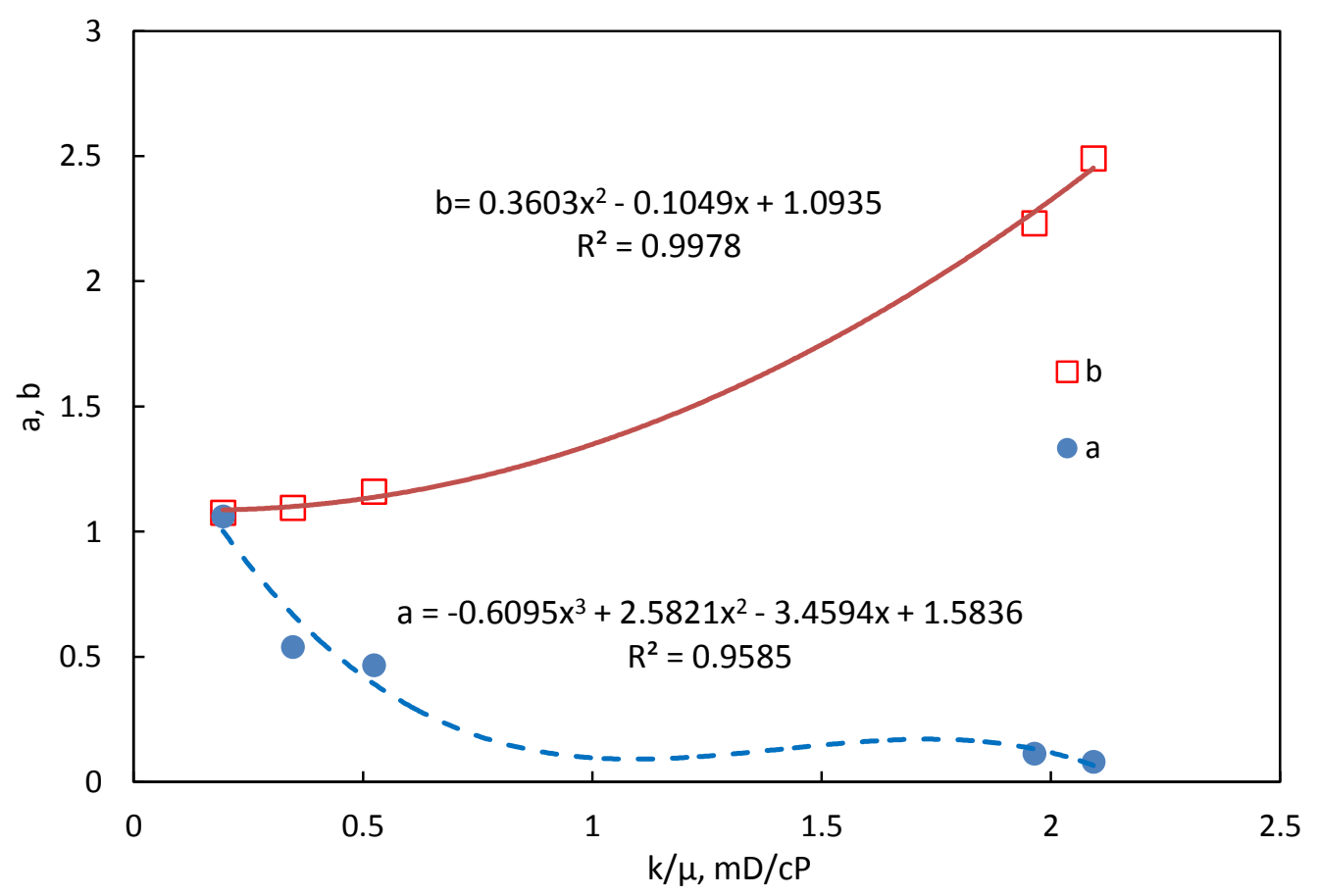

4

Fig. 4 Correlations of coefficient $a$ and $b$

\section{Vertical well production performance considering low velocity non-Darcy flow}

The vertical well production performance is studied by using a radial model. Based on material balance and the low velocity non-Darcy flow equation, the mathematical model is given as 


$$
\frac{1}{r} \frac{\partial}{\partial \mathrm{r}}\left(\left(\frac{1}{1+a \mathrm{e}^{-b\left|\frac{\partial p}{\partial r}\right|}}\right) r \frac{\partial \mathrm{p}}{\partial \mathrm{r}}\right)=\frac{\phi \mu c_{t}}{k} \frac{d p}{d t}
$$

2 where $\phi$ is the porosity and $c_{t}$ is the total compressibility.

3 In order to ensure the stability of numerical solution, a logarithmical transformation is used

$$
r=r_{w} e^{x}
$$

$5 \quad$ Combining equations (4) and (5), we can get

$$
\frac{\partial}{\partial x}\left(\left(\frac{1}{1+a \mathrm{e}^{-b \frac{1}{r_{w} e^{x}}\left|\frac{\partial \mathrm{p}}{\partial \mathrm{x}}\right|}}\right) \frac{\partial p}{\partial x}\right)=\frac{r_{w}^{2} e^{2 x} k}{\phi \mu c_{t}} \frac{\partial p}{\partial t}
$$

7 The boundary conditions of a constant wellbore flowing pressure and a closed drainage are 8 used in this model. The model can be solved by using the finite difference method. The 9 coefficients in the right hand side of Equation (6) are treated explicitly for the simplicity. The 10 details on numerical solutions are given in Appendix A. The model parameters are given in 11 Table 2. 
Table 2 Parameters of vertical well model

\begin{tabular}{|l|l|l|l|}
\hline Porosity & 0.05 & Oil viscosity & $0.3 \mathrm{cP}$ \\
\hline Permeability & $0.001 \mathrm{mD}$ & Total compressibility & $0.01 \mathrm{MPa}^{-1}$ \\
\hline Initial pressure & $20 \mathrm{MPa}$ & Gridblock size & $50 * 1 * 1$ \\
\hline Bottom hole pressure & $10 \mathrm{MPa}$ & Thickness & $50 \mathrm{~m}$ \\
\hline Radius of drainage area & $50 \mathrm{~m}$ & Well bore radius & $0.1 \mathrm{~m}$ \\
\hline Initial water saturation & 0.2 & Irreducible water saturation & 0.2 \\
\hline
\end{tabular}

According to equation (3a) and (3b), the non-Darcy coefficient is given by

$$
a=1.58
$$

$$
b=1.09
$$

The production rates and recovery factors of Darcy and non-Darcy flow are presented in Fig. 5 and Fig. 6. The production rate of a vertical well in this kind of reservoir is really small and unprofitable because of the low permeability. Because of the low production rate, the ultimate oil recovery factor is less than $3 \%$ for 4500 days production. Vertical wells can only control a really

9 limited reservoir reserve and the extra low well productivity results in its inadaptability in the development of shale and tight reservoirs. For the studied period, the production rate of a vertical

11 well considering low velocity non-Darcy is smaller than the Darcy flow but the decreasing rate is 12 slower than that of Darcy flow. The dominate flow regimes for both scenario are transient radial 13 flow, which are shown as straight lines in Fig. 5. The ultimate oil recovery (at 4500 days) of 14 non-Darcy is approximately $48 \%$ of Darcy flow oil recovery.

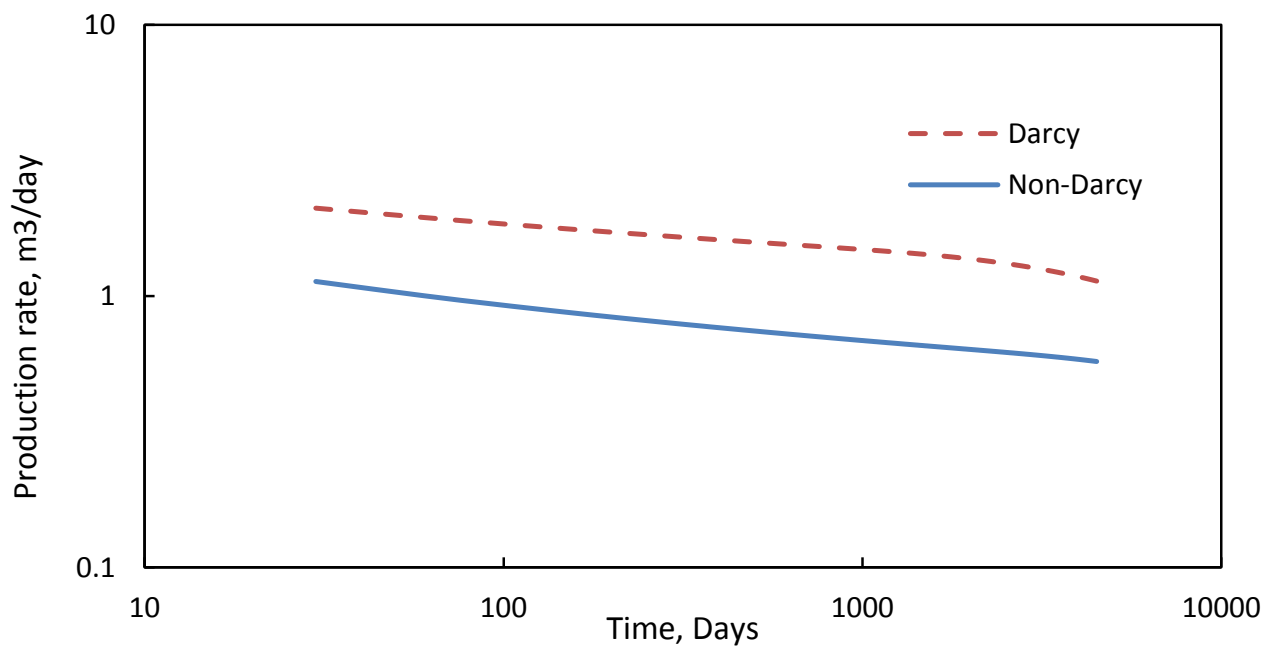


Fig. 5 Production rate of a vertical well for Darcy and non-Darcy flow

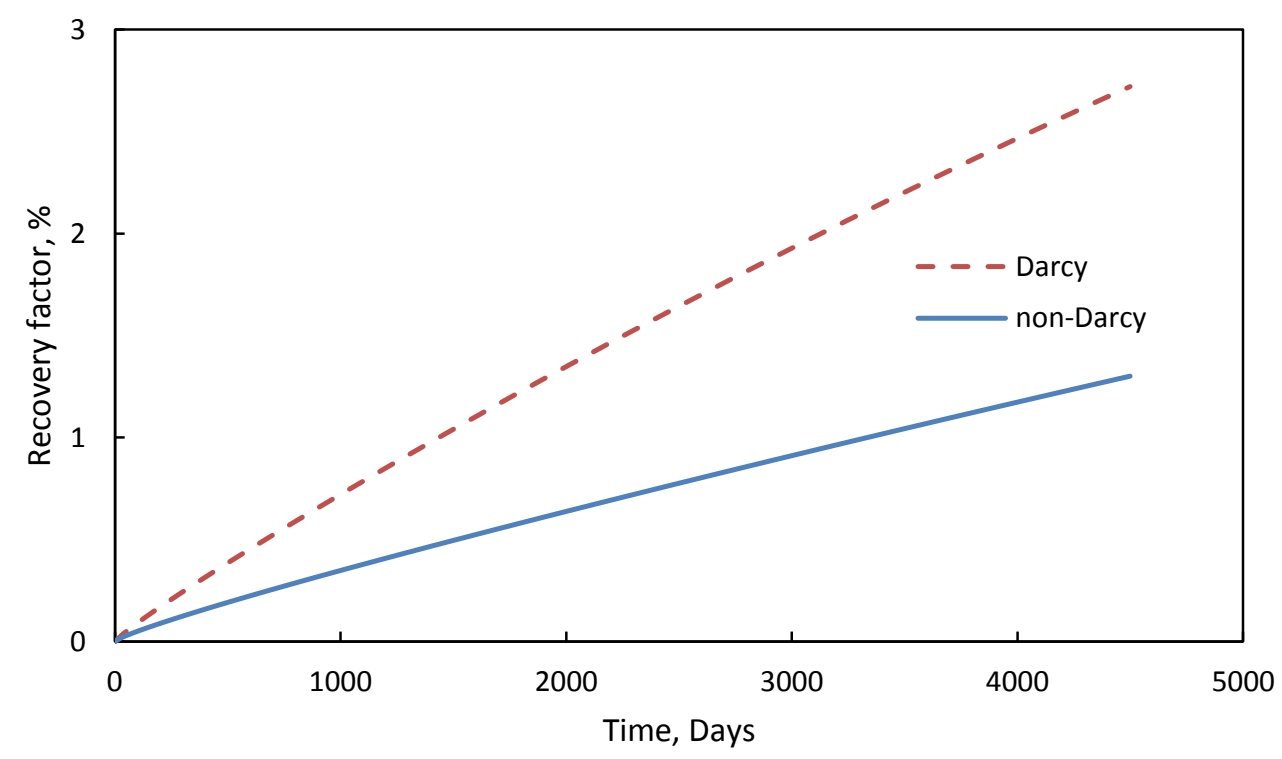

2

Fig. 6 Recovery factor of a vertical well for Darcy and non-Darcy flow

\section{Production performance of a horizontal well with multi-fractures considering low velocity non-Darcy flow}

Shale and tight oil reservoirs are often produced by multi-fractured horizontal wells. Within the stimulated reservoir volume (SRV), each fracture can be divided into several linear flow regions as described in Fig. 7. The red box represents a half fracture flow area which is subdivided into 50 blocks. Linear flow from these blocks into the half fracture is assumed. Only the flow within the half fracture area is modelled.

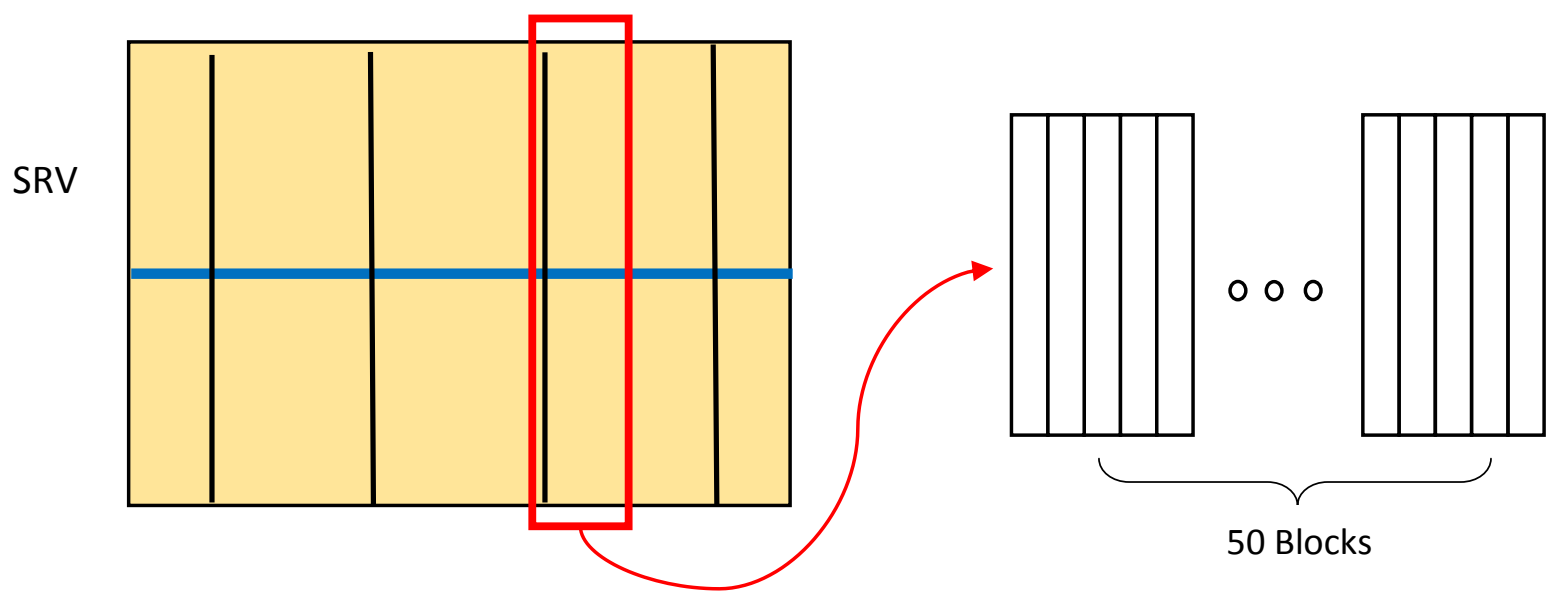

Fig. 7 Schematic of a shale oil reservoir model

Considering the low velocity non-Darcy phenomenon, the linear flow region model can be established as 


$$
\nabla \cdot\left(\left(\frac{1}{1+a \mathrm{e}^{-b|\nabla p|}}\right) \nabla p\right)=\frac{\phi \mu c_{t}}{k} \frac{d p}{d t}
$$

The boundary conditions of a constant wellbore flowing pressure and a closed drainage are also used in this model. The reservoir parameters can be found in Table $\mathbf{3}$ and the non-Darcy 4 parameters are the same as Equation (7a) and (7b). The details on numerical solutions are also 5 given in Appendix A.

Table 3 Parameters of multi-fractured horizontal well model

\begin{tabular}{|l|l|l|l|}
\hline Porosity & 0.05 & Oil viscosity & $0.3 \mathrm{cP}$ \\
\hline Permeability & $0.001 \mathrm{mD}$ & Total compressibility & $0.01 \mathrm{MPa}^{-1}$ \\
\hline Initial pressure & $20 \mathrm{MPa}$ & Fracture stage number & 20 \\
\hline Bottom hole pressure & $10 \mathrm{MPa}$ & Gridblock size & $50 * 1 * 1$ \\
\hline Fracture spacing & $100 \mathrm{~m}$ & Production time & 4500 Day \\
\hline Across areas & $200 * 50 \mathrm{~m}^{2}$ & Time step & 1 Day \\
\hline Initial water saturation & 0.2 & Irreducible water saturation & 0.2 \\
\hline
\end{tabular}

7 The production rates of Darcy flow and non-Darcy flow are presented in Fig. 8. The 8 production rate is plotted in a log-log plot. The well productivity is highly improved by using 9 mulita-fractured horizontal wells and both the production rate of Darcy and non-Darcy are much 10 higher than the vertical well. According to the figures, the production flow rate of Darcy flow is 11 higher than the flow rate of non-Darcy flow in the beginning. However, the Darcy flow changes 12 from transient flow regime to pseudo steady flow regime earlier than non-Darcy flow, which 13 leads to the production rate of non-Darcy flow being higher in the later production period (after 142700 days).

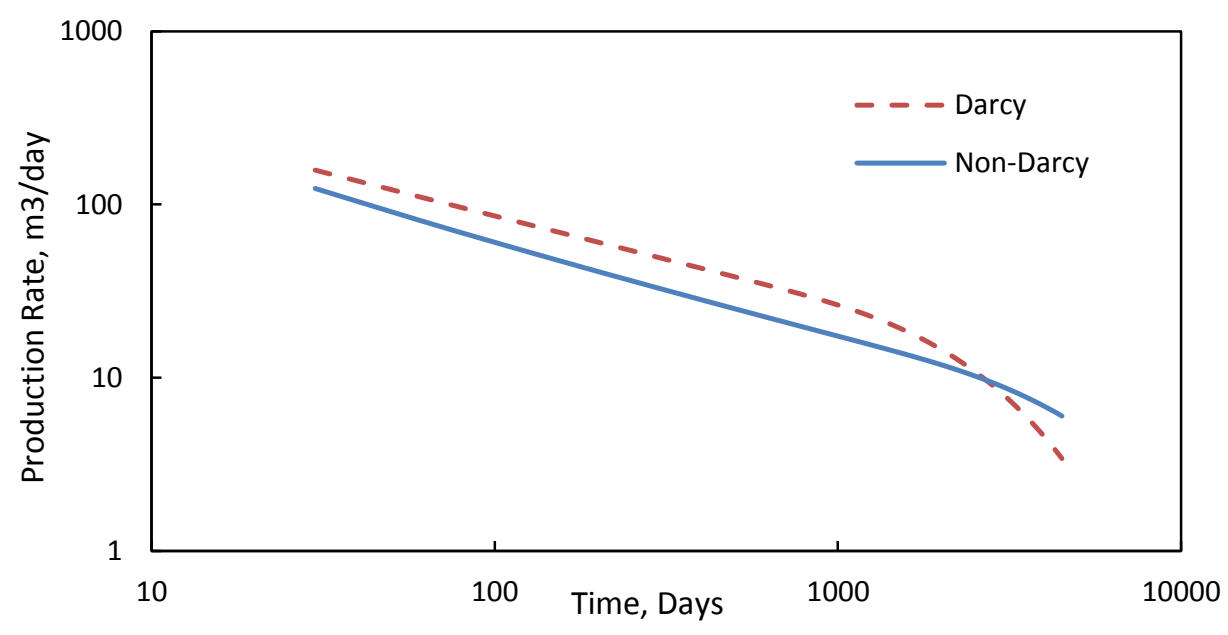


Fig. 8 Production rate of Darcy and non-Darcy flow

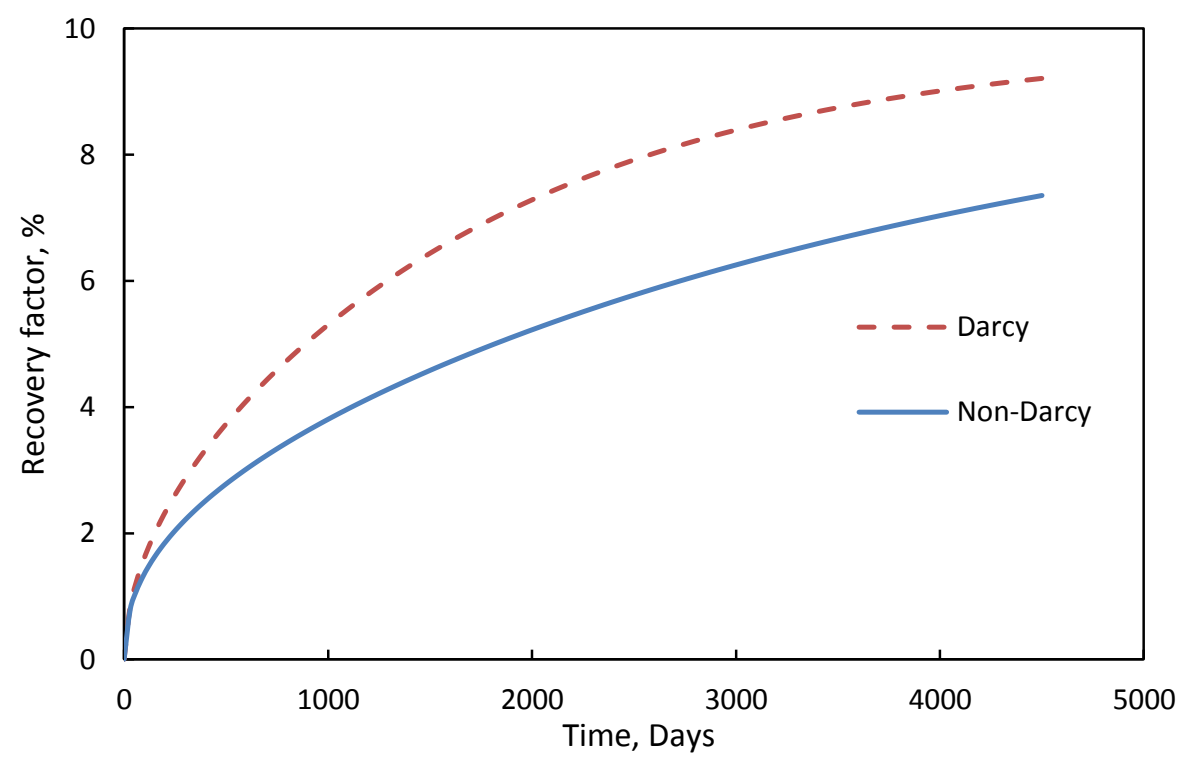

Fig. 9 Oil recovery factor of Darcy and non-Darcy flow

Also, the oil recovery factors of non-Darcy and Darcy flow are shown in Fig. 9. According to the figure, the Darcy flow presents a higher oil recovery factor, and the non-Darcy equation exhibits a smaller value. The ultimate oil recovery factor of non-Darcy flow is approximately $80 \%$ of Darcy flow. Compared with the vertical well model, the non-Darcy effect is reduced by using multi-fractured horizontal wells to change the radial flow to linear flow.

\section{Conclusions}

A careful study has been conducted to analyze and model low velocity non-Darcy flow phenomenon in tight or shale reservoirs. Based on this study, the following conclusions may be drawn.

1. Low velocity non-Darcy flow exists in shale and tight reservoirs because of the rock liquid interactions so that there is a boundary layer, but TPG does not exist. There are the nonlinear flow part and the linear flow part in the non-Darcy flow regime, and the nonlinear flow regime starts from the zero pressure gradient and zero velocity.

2. A low-velocity non-Darcy model is introduced and the corresponding parameter correlation is also derived by fitting some of high accurate experimental data.

3. Using this model, both a vertical well model and a multi-fractured horizontal well model are used to compare the well production performance with and without considering the nonDarcy flow phenomenon. 
4. The productivity of a vertical well is too small to be profitable, but the productivity of a multi-fractured horizontal well is greatly improved. The non-Darcy effect has a bigger impact on vertical wells than on multi-fractured horizontal wells. Multi-fractured horizontal wells exhibit a significant advantage in developing shale and tight reservoirs.

\section{Acknowledgement}

The work presented in this paper is supported by the Department of Energy under Award Number DE-FE0024311.

\section{References}

[1] Javadpour, F. 2009. Nanopores and apparent permeability of gas flow in mudrocks (shales and siltstone). Journal of Canadian Petroleum Technology, 48(08), 16-21.

[2] Civan, F. 2010. Effective correlation of apparent gas permeability in tight porous media. Transport in porous media, 82(2), 375-384.

[3] Cao, B. Y., Sun, J., Chen, M., \& Guo, Z. Y. 2009. Molecular momentum transport at fluidsolid interfaces in MEMS/NEMS: a review. International journal of molecular sciences, 10(11), 4638-4706.

[4] Majumder, M., Chopra, N., Andrews, R., \& Hinds, B. J. 2005. Nanoscale hydrodynamics: enhanced flow in carbon nanotubes. Nature, 438(7064), 44-44.

[5] Whitby, M., \& Quirke, N. 2007. Fluid flow in carbon nanotubes and nanopipes. Nature Nanotechnology, 2(2), 87-94.

[6] Javadpour, F., McClure, M., \& Naraghi, M. E. 2015. Slip-corrected liquid permeability and its effect on hydraulic fracturing and fluid loss in shale. Fuel, 160, 549-559.

[7] Li, S., Dong, M., \& Li, Z. 2009. Measurement and revised interpretation of gas flow behavior in tight reservoir cores. Journal of Petroleum Science and Engineering, 65(1), 8188.

[8] Dong, M., Li, Z., Li, S., \& Yao, J. 2012. Permeabilities of tight reservoir cores determined for gaseous and liquid CO 2 and C 2 H 6 using minimum backpressure method. Journal of Natural Gas Science and Engineering, 5, 1-5.

[9] Ghanizadeh, A., Amann-Hildenbrand, A., Gasparik, M., Gensterblum, Y., Krooss, B. M., \& Littke, R. 2014. Experimental study of fluid transport processes in the matrix system of the European organic-rich shales: II. Posidonia Shale (Lower Toarcian, northern Germany). International Journal of Coal Geology, 123, 20-33. 
[10] Moghadam, A. A., \& Chalaturnyk, R. 2015. Analytical and Experimental Investigations of Gas-Flow Regimes in Shales Considering the Influence of Mean Effective Stress. SPE Journal. SPE-178429.

[11] Huang, Y., Yang, Z., He, Y., Wang, X., \& Luo, Y., 2013. Nonlinear porous flow in low permeability porous media. Mechanics and Practice. 35(5), 1-8.

[12] Miller, R. \& Low, P., 1963. Threshold gradient for water flow in clay systems. Soil Science Society of America Journal, 27(6), 605-609.

[13] Prada, A. \& Civan, F., 1999. Modification of Darcy's law for the threshold pressure gradient. Journal of Petroleum Science and Engineering, 22(4), 237-240.

[14] Huang, Y., 1998. Mechanism of flow in low permeability reservoirs. Petroleum Industrial Press.

[15] Yang, Z., 2005. Porous media flow mechanics for low permeability reservoirs and its application, Doctoral Dissertation, Chinese Academy of Sciences.

[16] Li, A., Zhang, S., Liu, M., Wang, W., \& Zhang, L. 2008. A new method of measuring starting pressure for low permeability reservoir. Journal of China University of Petroleum (Edition of Natural Science), 32(1), 68-71.

[17] Li, S., Cheng, L., Li, X. \& Hao, F., 2008. Nonlinear seepage flow of ultralow permeability reservoirs. Petroleum Exploration and Development, 35(5), 606-612.

[18]Zeng, B., Cheng, L., \& Hao, F., 2010. Experiment and Mechanism Analysis on Threshold Pressure Gradient with Different Fluids. Society of Petroleum Engineers. SPE- 140678.

[19] Wang, X., Yang, Z., Sun, Y., \& Liu, X. 2011. Experimental and theoretical investigation of nonlinear flow in low permeability reservoir. Procedia Environmental Sciences, 11, 13921399.

[20] Yang, Z., Yu, R., Su, Z., Zhang, Y. \& Cui, D., 2010. Numerical simulation of the nonlinear flow in ultra-low permeability reservoirs. Petroleum Exploration and development, 37(1), 94-98.

[21] Yang, Z., Liu, X., Xu, X., Zhang, Y., \& Wang, X. 2013. Study on Physical Simulation Experimental Technology of Ultra-low Permeability Large-scale Outcrop Model. International Petroleum Technology Conference. SPE-16875. 
[22] Xu, J., Jiang, R., Xie, L., Wang, R., Shan, L. \& Li, L., 2012, January. Non-Darcy flow numerical simulation for low-permeability reservoirs. In SPE Europec/EAGE Annual Conference. Society of Petroleum Engineers. SPE-154890.

[23] Wang, S., Feng, Q., Zha, M., Lu, S., Qin, Y., Xia, T., \& Zhang, C. 2015. Molecular dynamics simulation of liquid alkane occurrence state in pores and slits of shale organic matter. Petroleum Exploration and Development, 42(6), 844-851.

[24] Liu, D., Yue, X., Yan, S., Hou, J., Wang, L. \& Zhang, J., 2005. The effects of adsorbed water layer on flow mechanism in low permeability reservoirs. Petroleum Geology and Recovery Efficiency, 12(6), 40-42.

[25] Xu, S., \& Yue, X., 2007. Experimental research on nonlinear flow characteristics at low velocity. Journal of China University of Petroleum (Edition of Natural Science), 31(5), 6063.

[26] Song, F., Liu, C., \& Wu, B., 2001. The fast transient measurement of threshold pressure gradient. Acta Petrolei Sinica, 22(3), 67-70.

[27]Liu, Y., Ding, Z., \& He, F., 2002. Three kinds of methods for determining the start-up pressure gradients in low-permeability reservoir. Well testing, 11(4), 1-4.

[28] Yang, Q., Nie, M., \& Song, F., 2004. Threshold pressure gradient of low permeability sandstone. J Tsinghua University (Science Technology), 44(12), 1650-1652.

[29] Yan, M., Wu, C., \& Wang, Y., 2006. Tendency of Starting Pressure Gradient Changes in Heterogeneous Reservoirs. Journal of Oil and Gas Technology, 28(3), 129-130.

[30] Hao, P., Xiang, J., Wang, W., \& Kang, Y., 2008. Study on the relationship between starting pressure gradient and permeability in low permeability reservoirs. Journal of Oil and Gas Technology, 28(3), 315-317.

[31] Li, C. \& Zhu, S., 2013. Another discussion on starting pressure gradient. Lithologic Reservoirs, 25(4), 1-5.

\section{Appendix A--Implicit finite difference numerical solutions for our model}

Both the vertical well and multi-fractured well models are solved using finite difference method. The vertical well and the multi-fractured well models are treated as radial flow and linear flow, respectively. According to equation (6) and (8), the unified formula is expressed as

$$
\frac{\partial}{\partial x}\left(f \frac{\partial p}{\partial x}\right)=g \frac{\partial p}{\partial t}
$$

We discretize equation (A-1) to get 


$$
f_{i+\frac{1}{2}}^{n+1}\left(p_{i+1}^{n+1}-p_{i}^{n+1}\right)+f_{i-\frac{1}{2}}^{n+1}\left(p_{i-1}^{n+1}-p_{i}^{n+1}\right)=\frac{\Delta x^{2}}{\Delta t} g_{i}\left(p_{i}^{n+1}-p_{i}^{n}\right)
$$

2 Rearrange equation (A-2) as

$$
f_{i+\frac{1}{2}}^{n+1} p_{i+1}^{n+1}-\left(f_{i+\frac{1}{2}}^{n+1}+f_{i-\frac{1}{2}}^{n+1}+\frac{\Delta x^{2}}{\Delta t} g_{i}\right) p_{i}^{n+1}+f_{i-\frac{1}{2}}^{n+1} p_{i-1}^{n+1}=\frac{\Delta x^{2}}{\Delta t} g_{i} p_{i}^{n}
$$

4 where, $n$ is the time step index; $i$ is grid index; $\Delta t$ and $\Delta x$ are time step interval and grid block 5 size, respectively.

6 For linear flow,

$$
\begin{array}{r}
f_{i \pm \frac{1}{2}}^{n+1}=\frac{1}{1+a \mathrm{e}^{-b \frac{\left|p_{i \pm 1}^{n}-p_{i}^{n}\right|}{\Delta x}}} \\
g_{i}=\frac{\phi \mu c_{t}}{k}
\end{array}
$$

9 For radial flow,

$$
f_{i \pm \frac{1}{2}}^{n+1}=\frac{1}{1+a \mathrm{e}^{-b \frac{\left|p_{i \pm 1}^{n}-p_{i}^{n}\right|}{r_{w} e^{i \Delta x}\left(e^{\Delta x}-1\right)}}}
$$

$$
g_{i}=\frac{k r_{w}^{2} e^{2 i \Delta x}}{\phi \mu c_{t}}
$$

12 This is for the implicit numerical method. Given the initial conditions, we can apply the above 13 equations for every grid to get the linear equation group and then solve it to update the pressure 14 distribution for the next time step. The corresponding production rate is obtained by applying 15 Darcy's equation at the first block. We continue this process until the preset production time is 16 satisfied. 